dasses have a longer period of existence meted out to them after the onset of the disease than have the poorer classes. The explanation of this may be the earlier recognition of the disease in the wealthier classes and the earlier resort to care and treatment.

Annexed are notes illustrative of three typical cases, with recovery in two.

CASE 1. Undoubted general paralysis with typical and marked mental as woll as physical symptoms of the disease.The following characteristic letter was written two or three months after onset whilst under care: "I am going to astonish the whole world this week; the papers will be full of it. I am going to reform the world-England to be made a paradise. Work for all the unemployed; no more taxes, workhouses or prisons required. All diseases will be banished; there will be simply a few paying hospitals. No one to be married before they are twenty-four years of age, women twenty-one years. The first thing to do is to get together all the vagabonds, thieves, drunkards, and wifebeaters, and I shall have them punished with a cat-and-ninetails. The sea to be brought all over England, also electric light, good roads to be made, plants, trees, and wild tlowers on the banks. Electric tramcars. I shall have plenty of money to do what 1 like with. Your dad will 'be a bishop' and my private chaplain. I have learnt to sing and play anything on the piano; you will hardly know me, I am so improved. Nice church and cathedral will be built. $\mathrm{I} \mathrm{am}$ going all over the world and you shall come to some of the best places with me. Address to me, Grand Hotel, Charing Cross." At the end of six months, arrest having been in progress for some time, a consultation among leading psychologists and neurologists was held in London, with the result that no trace of the mental disease was discovered. A three months' probation followed, at the end of which time the patient was discharged recovered.

CASE 2.-In this case equally typical symptoms presented themselves, but an enumeration of them would prove too lengthy. The patient believed he was making $£ 190,000$ per diem, \&c.; six months later an inquisition in lunacy was held by a master in lunacy on the request of the family, but by the time it was held there was no evidence to produce of existing insanity. Three months later ordinary work was resumed in London and at the end of another three months the patient, remaining perfectly well mentally, was also discharged recovered.

CASE 3.-This case was of about six years' duration and during a considerable portion of the time the disease was in a state of arrest.

West Malling, Kent.

\section{AXIS-TRACTION FORCEPS.}

\section{By WALTER COLQUHOUN, M.A., M.B., C.M. GlasG.}

THE matter of this paper, the subject of which has caused me considerable thought, may not appear inopportunely at the present moment, when so many busy practitioners are giving up their old forceps for forceps guaranteed to pull in the direction of the pelvic axis. If I may seem to some readers to deal with points which have been thrashed out elsewhere at greater length my answer is that they did not seem to be known to able practitioners, my friends, and, further, that they have evidently been missed more or less by inventors whose forceps are in good enough repute. Dr. Playfair pertinently remarks concerning forceps: "It would be a wearisome and unsatisfactory task to dwell on all the modifications of the instrument which have been made, which are so numerous as to make it almost appear as if no one could practise midwifery with the least pretension to eminence unless he has attached his name to a new variety of forceps." Nor can it be expected that those who dwell in the valleys will altogether escape the epidemic ranging among dwellers on obstetric heights. In many a humble medical home in Scotland some seclnded eupboard contains weapons which may probably be hung on the walls by female posterity and be pointed to with pride as relics of the battle of Bannockburn. I also invented a beautiful pair of forceps, superior to anything in existence, out convalescence fortunately setting in while the matter was at the paper stage I began to consider the essentials demanded from axis-traction forceps, and also how those demands are met by the various forms in use. It is $\mathbf{m y}$ purpose in this paper to deal with the general question from that point of view.

A pair of forceps is said to act in three ways: (1) as a tractor; (2) as a lever; and (3) as a compressor. An axistraction forceps (since it is inconvenient to use two different pairs in the same case) should combine these three properties with that of confining traction at each point to the direction of the pelvic axis. To these properties attempts are now made to provide for free movement of the foetal head in flexion, extension, and rotation, and in addition it is demanded that the forceps should act as a guide to the fotus and as an indicator of the direction of traction. Let me consider the points in detail

Direction of traction. - In many instruments the forceps are used, but used erroneously, as an indicator of the direction in which traction should be made; that is to say, the pelvic curve of the instrument is considered to coincide with the pelvic axis, and traction being made on the instrument after locking by means of a tractor which enables it to swing more or less freely it is supposed to slide out keeping to the pelvic curve. The instruction given with most instruments is that the bar of the tractor should be kept parallel to the handles of the forceps. Now, to pull in the direction of the axis the pull must be given at each instant in the direction of the tangent to the pelvic curve at the point where it passes the centres of the fenestræ. Accordingly, if it is intended to use the handles of the forceps as an indicator of the direction of traction they should be bent backwards. A glance at Tarnier's excellent instrument will show that the part of the forceps corresponding to the handles of our instruments is practically parallel to the curve at the centre of the fenestra. In Neville's forceps also, Rotunda pattern, an arrow indicates the direction of pull which is inclined backwards from the handles. In connexion with this point the following quotation from Barnes's "Obstetric Operations" is interesting: "Dr. Aveling curves the handles of a short double-curved forceps backwards, thus increasing, he affirms, the tractile power." Here the idea does not seem to have been to change the direction of the pull, but rather to approach the point to which traction was applied to the line representing the axis, just as is done in axis-traction instruments by curving the traction rods backwards. The direction of traction altogether depends on the direction in which the pull is made and not at all on the point at which it is made. Thus it is of little use to curve the traction rods backwards if the pull is in the wrong direotion. They are curved backwards because the forceps and the child's head forming a rigid lever, the fulcrum of which is above the point of application of the forceps, if any force be applied in a given direction to the handle of the forceps the point of application of that force tends to lie on a line drawn through the fulcrum in the given direction. Hence the application of a force at the handles of the forceps, even when applied in the right direction, may wrongly cause or prevent flexion or extension, or, what is of more serious consequence, may press the forceps and head injuriously against the soft parts of the mother. The curving of the traction rods backwards tends to place the point of application of the pull on the line of direction of the force which passes through the fulcrum. If this condition be satisfied and the pull be at each instant in the right direction it is of little importance whether the traction rods be attached high up or not.

Rotation, flexion, and extension.-Why, then, is it asserted to be a distinct advantage in practice to have the traction rods attached high up? I have heard it asserted that such an arrangement allows of free flexion or extension, but I hope to show presently that there is little truth in the assertion. If there is any advantage in the high insertion of the traction rods it seems to me to lie in the fact that such an arrangement allows the forceps to act as guide to the fotal head more easily and tends to minimise the disadvantage accruing from wrong application of force at the end of the long rigid lever formed by head and forceps. Flexion and extension occur at the proper stages during delivery by rigid forceps and as a matter of necessity. It is claimed that some of the recent axis-traction forceps by allowing the forceps to swing about the points of application of the traction rods allow free flexion and extension and yet the inventors of the instruments use them as indicators of the direction of traction. As a matter of fact, forceps which fit the pelvic curve and are rigidly connected with the fotus can have no free swing, and flexion and extension, except within 
very small limits, occur at the same places during delivery and in the same manner as when rigid forceps are used, traction being applied by the handles. Thus extension, for example, could take place without advance of head and forceps only by the forceps leaving the pelvic curve.

$A$ point which is not much dwelt on by inventors is that forceps which are best suited for axis traction, having a full pelvic curve, are unsuited for rotation and that if they rotate they are no longer axis-traction forceps. Indeed, the only way to restore true axis traction in such cases would be to rake them off after rotation and obtain a new grip. Forceps with a pronounced pelvic curve are evidently intended to be put on in the transverse diameter, and if rotated to any extent the pelvic curve is no longer a guide or indicator but rather a hindrance. Hence the wisdom shown by Simpson in making his forceps with a modified pelvic curve to allow of some rotation and slight movement of flexion or extension. It seems to me a problem worthy of grave attention whether for general use the axis-traction forceps coming so much into vogue are not more dangerous than Simpson's long forceps used with some knowledge and caution. Rigby in his "System of Midwifery" says: "The forceps is the simplest imitation of nature, for, in fact, it is notbing more than a pair of artificial hands introduced one on each side of the head." Now when a man grasps the handles of the forceps the instrument may be regarded as a continuation of his own hands. There is direct connexion between his hands and the footus, he feels when it moves or yields, estimates more accurately the force he is using, and by his great leverage can, guided by his knowledge, help its progress at a difficult point. Using the axistraction forceps is like putting another man's hands into the pelvis to grasp the head and then pulling on his coat-tails. I am so convinced $o$ the advantage of a rigid connexion with the fœetus that, apart from other considerations, I consider that to be one of the advantages of Murdoch Cameron's antero-posterior forceps. It is quite common for medical men to complete delivery by pulling on the traction bar. Now I confess that if the head is high in the pelvis, and indeed until it has reached the floor, it is of advantage to have an indicator of the direction of the axis and also the power of pulling freely in the direction of the axis, but $I$ am of opinion that in every case both hands should be used, one grasping the handles of the forceps and the other the traction handle. The hand which grasps the handles of the forceps can apply leverage where necessary, steady the progress of the foetus, and obtain information of that progress which would not be obtained by merely pulling on the traction handle. When the head has reached the floor of the pelvis it is especially necessary, for the sake of the perineum, among other reasons, to complete delivery without having recourse to the traction handle. In his "System of Midwifery," 1844, Rigby writes: "In extracting the head we must bear in mind the part of the pelvis in which it is impacted and make our efforts in the direction of its axis ; we must also recollect the curved form of the instrument, and that we must not pull in the direction in which the handles point, but rather hold them firmly in one hand and by pressing against the middle of the forceps with the othor guide the head downwards and backwards into the carity of the pelvis. We shall thus make our extractive effort in the direction of the upper portion of the blades. or that part which has the chief hold upon the head." (The italics are mine.) Here there is perfect axis traction arranged for without any great apparatus but simply by means of the ordinary forceps used with the good sense and ingenuity of a practical man, and his axis traction would be much more perfect than that of a practitioner who delivered by simply pulling on the traction handle of one of the latest instruments. Traction rods enable the operator to use the second hand to great advantage, but the more important band is the one which grasps the handles of the forceps. The forceps in Rigby's hands had another important use, for he continues: "Whilst extracting we should, as with the straight forceps, slowly move the handles from side to side and even make them describe a circle. We thus not only use the forceps as a simple extracting instrument, but make it act as a lever in every direction and greatly facilitate the advance of the head, even under circumstances of considerable impaction."

It was the considerations I have set forth which caused my forceps to be stillborn. I was providing for free movements of rotation, flexion, or extension, by placing immediately below each fenestra a swivel and a hinge, which could both be unlocked from the handles. I am now convinced. that while it is a benefit to be able to use the curved tractiom rods, the rigidity of the instrument and its simplicity shonle be interfered with as little as possible.

Glasgow.

\section{PARALYSIS AGITANS;}

WITH AN ACCOUNT OF A NEW SXMPTOM.

BY PURVES STEWART, M.A., M.D. EDIN., M.R.C.P. LOND.,

SENIOR HOUSE PHIYSTCIAN TO THE NATIONAI HOSPITAL FTOR THE PARALYSED AND EPILEPTIC, QUEEN-SQUARE, BLOOMSBURY, LONDON, W.C.

EIGHTx years ago Parkinson wrote his classical description of paralysis agitans. So little has been added to its symptomatology since and the disease now appears at first sight to be, clinically at least, so thoroughly worked out that to many it may seem a superfluous task to traverse once more a subject so well worn. The following paper, therefore, must be regarded as merely supplementary to the descriptions in the text-books, not in any sense as a substitute for them.

Within the past two years I have had opportunities of studying a number of patients, 28 in all, suffering from paralysis agitans and it is upon personal observations on these cases that the following remarks are based. Although the number of cases is not large enough to permit of any statistical references being founded upon them alone, yet the fact that they have been examined and compared by one person renders the value of the observations fairly uniform, whilst the cases are sufficiently numerous to justify me in drawing certain clinical conclusions. Of these 28 cases, 17 occurred in men and 11 in women. This greater frequency among male patients is in entire agreement with the combined statistics of a large number of cases seen by other physicians, which show the disease to be much more frequent in the male sex than in the female, the proportion being about 2 men to 1 woman.

The age of onset of symptoms in my series of cases is instructive. It ranges from twenty-two years to seventy-three years, the distribution being as follows:-In 1 case the earliest symptom appeared at the age of twenty-two years: in 1 case at thirty years; in 1 case at thirty-three years ; in 2 cases between the ages of thirty-five and forty years; in 3 cases between forty and forty-five years; in 6 cases: between forty-five and fifty years; in 7 cases between fifty and fifty-five years; in 4 cases between fifty-five and sixty years; in 2 cases between sixty and sixty-five years; and in 1 case at the age of seventy-three years. Thus 23 cases out of 28 -i.e., over 82 per cent.-commenced after the age of forty years.

A family history of nervous disease was obtained in only a few instances (in 6 cases out of 28). In 4 of these 6 cases there was epilepsy or insanity in the patient's brother or sister; in 3 of the 6 cases a relative had actually suffered from paralysis agitans-a maternal aunt in one case ${ }_{r}$ a paternal grandfather in another, and a sister in a third. As to exciting cause, 6 patients gave a history of fright or emotional disturbance. Thus, for example, in one case the earliest symptom-shaking of the left thumb-showed itself after a shock occasioned by a sister becoming insane. Another patient was at a menagerie when a lion escaped from its cage and caused considerable alarm amongst the spectators. On the next day the patient's illness is said to have commenced, his first symptom being stiffness of the left leg. Another patient was threatened as a "blackleg" by his fellow-workmen on the railway who were on strike and ever afterwards he found his right hand stiff and his handwriting unusually slow. Another patient blamed the shock of having a tooth extracted as being the antecedent cause of her illness, the earliest symptom in her case being tremor of the left hand. Worry or overwork was assigned as the exciting cause in 3 cases : 3 were said to have followed an attack of influenza; and one patient had an attack of right hemiplegia a few weeks before the tremor of paralysis agitans appeared in his left hand. One man had his foot trodden on by a horse a year before the onset of tremor in that foot. One woman's symptoms came on after a confinement at the age 